\title{
The power of academic relationships
}

Friends are as companions on a journey, who ought to aid each other to persevere in the road to a happier life. - Pythagoras

$\mathrm{W}$ hile reading medical journals, I always look at the author affiliations for each paper and try to imagine how certain groups came about. My curiosity stems from my belief that beyond the successful publication, these author affiliations are a testimony to academic relationships; they reflect the journey, which I find far more interesting than the paper itself.

Did the initial idea arise typically: friends chatting over a pizza, colleagues in the same department or teacher-student combinations? Are these old classmates in different countries who've kept in touch over the career rat race? Or is their tale more Hollywood worthy: an idea on the back of a napkin, or far-flung authors in totally different disciplines bringing a serendipitous meet-up online, through a friend-of-a-friend or at a conference, to ultimate fruition?

Then I imagine the team's path to publishing. One of the initial folks reaches out to an old friend who has built his career around the subject, or a research supervisor agrees to mentor a summer student keen to make a difference. Together, the team searches, writes and revises; shares thoughts; and pieces it all together. There are countless discussions, phone calls and emails, small victories and self-doubt, personal growth and despair. Suddenly, it all comes together and before they know it, it's off to submission and hopefully acceptance. Then, in all of its printed glory, it's not just a paper; instead, it's a standing testimonial to whatever relationships made it happen.

The human side also defines this process. Drawing on my own experiences, I often wonder how each team worked, as I scan the institutions and cities they hail from. Was one team member always "terrible" with e-mail? Were there constant Skype meetings? Did one member always "drop in" to the lab late? Were there celebrations for the little victories: an oral presentation

consult, regarding a difficult case, with a physician who was a groomsman at my wedding. Our other friend on the paper was the senior resident who later admitted the patient for treatment. ${ }^{3}$ I also remember getting the authorship forms signed, which involved faxes and emails, but also a visit to a colleague's busy clinic, spending a scant five minutes catching up.

Beyond their contents, our papers stand for our friendships and the memories involved. That the memories grow distant reminds me that doctors are notoriously terrible at keeping in touch. We're always too busy, slaving away at work, and we imagine that, eventually, we'll find time to call our old friend and figure out that good idea they had.

Truthfully, there's never at one conference, a poster at another?

I also wonder how the authors imagined their work. Did they think it innovative, or did they just want that first line on their CV? Did Olshansky and team meet monthly in a Chicago pub and declare "We've got a huge ground-breaking paper here, our kids are eating themselves to death?" or did they just show up to work day after day and trade emails?

My imaginings flow from my own opportunities and serendipitous relationships. I've published with friends I studied with in Baltimore; we discovered a shared passion for global health. ${ }^{2}$ While they're all over the United States now, just reading our paper brings me back to memories of brainstorms and hilarity in Baltimore row houses, imagining we could change the world. That led to spending time in Switzerland on elective together, with many a late night spent with a bottle of wine struggling away at yet another revision, the Alps outside our flat as the backdrop.

Another case report I published with two friends was the result of a corridor going to be a better time. It's worth a moment to consider our academic relationships, reaching out to tap their revolutionary power. The growing diversity of published affiliations shows that we have the collective ability to answer the hard questions.

It's a lot of work to put papers together with coauthors far and near. But the journey is ultimately rewarding, and we'll never know where our ideas and relationships will take us until we try.

\section{Lawrence Loh MD MPH}

Adjunct lecturer

Dalla Lana School of Public Health University of Toronto

Ottawa, Ont.

\section{References}

1. Olshansky SJ, Passaro DJ, Hershow RC, et al. A potential decline in life expectancy in the United States in the 21st century. N Engl J Med. 2005;352: 1138-45.

2. Loh LC, Rhee DS, Heckman JE, et al. Not just more global health - smarter global health. Can Fam Physician. 2012;58:376-8.

3. Loh LC, Rao RV, Ng DN. An uncommon, sinister vertebral fracture: early-onset multiple myeloma. Can Fam Physician 2012. In press.

CMAJ 2013. DOI:10.1503/cmaj.121199

All editorial matter in CMAJ represents the opinions of the authors and not necessarily those of the Canadian Medical Association. 